\title{
The Implementation of Virtual Studio Laboratory Based on Web
}

\author{
Ya Zhao, Xianmei Liu, Feng Tian \\ School of Computer \& Information Technology \\ NorthEast Petroleum University \\ Daqing 163318, China \\ zhaoyaya1980@163.com
}

\author{
Feng Tian \\ Ministry of Education Key Laboratory of Virtual \\ Reality Technology \\ Beihang University \\ Beijing 100083,China \\ lindaleiya@163.com
}

\begin{abstract}
The studio has extraordinary meaning of the personnel training of the specialty. According to the actuality and application demand of colleges and universities, we plan to construct a virtual studio laboratory. The paper introduces the system functional components of virtual studio laboratory, elaborates the realization of technologies of virtual studio laboratory, analyses the virtual studio laboratory's application meaning in teaching in the end. Appling the virtual studio laboratory in teaching, we can acquire well teaching effect. The virtual studio laboratory has definite promotional value, can be used in the education and teaching of film and television producing extensively.
\end{abstract}

Keywords- Virtual Studio, Virtual Laboratory, Virtual Experiment, Web, 3D Modeling, Human-Computer Interaction

\section{INTRODUCTION}

Now more and more colleges and universities set up the specialty direction of directing and producing of film and television program. It is well known that the studio has extraordinary meaning of the personnel training of the specialty direction. To most colleges and universities, the construction of studio needs fund and space. Being limited to fund and space, most of them haven't constructed real studio. It has turned out that the postgraduates are lacking in the master of knowledge and ability in this aspect.

As the product of the combination of several technologies: image processing techniques, audio processing techniques, virtual reality techniques and traditional studio chroma key techniques for the past few years, the virtual studio is a television program manufacture system. The virtual studio can perform real-time digital synthesis of virtual scene and activity image sequence, here the virtual scene is constructed by software and the activity image sequence is captured by vidicon. It makes real camera activities and virtual scene synchronous change, so as to realize the perfect combination of real prospect and virtual background. It can give full play to the program producers' imagination and creativity, improve the quality of programs, save space, reduce production cost, be used in the television widely now[1-4].

At the same time, as a result of the rapid development of network technology and virtual instrument technology, through the network to construct virtual laboratory has been possible. The virtual laboratory has some important advantages: construction low cost, providing living and vivid experiment environment. Through the network connection, the students can enter the virtual laboratory, can become a player in the virtual environment to play a role, can truly operate experiment equipments and carry on the concrete experiments[5]. It will bring positive effects in mobilizing the students' learning enthusiasm, the emphases and difficulties of the breakthrough of teaching, training the students' technical skills.

Considering all the advantages of virtual studio, if we introduce it into colleges and universities, use it in education television program producing and assisting teaching, we can enrich teaching content and strengthen the students' practical ability. The fact is: the professional virtual studio has high cost although it has abundant functions. The requirement of virtual studio of colleges and universities is not high. They just want to use it in teaching mainly. If we combine virtual studio with virtual laboratory, a virtual studio laboratory used in class and practice teaching can be constructed by us. It can be used to show the real studio environment and simulate real studio's functions. It also can be merged into the important class or experiment knowledge. The students can enter the studio laboratory freely, operate the equipments, review and consolidate correlative knowledge and operation skills. The use of virtual studio can resolve these problems such as: capital shortage and space shortage, and make the students learn in an interesting way simultaneously.

\section{SIMPLE INTRODUCTION OF VIRTUAL STUDIO LABORATORY}

The virtual studio laboratory falls into the category of virtual laboratory. Its' functions are not as many as virtual studio. It constructs a virtual studio laboratory experiment environment referring to virtual studio. Its' application emphasize particularly on virtual experiments and teaching.

The virtual studio laboratory constructed in this paper is based on web, which creates a visualization of $3 \mathrm{D}$ environment through the internet. A visualization of 3D object in it represents one kind of experiment object. Through the interactive operation such as: mouse click or drag, every student can do virtual experiment in the virtual studio laboratory as long as he is located in the web server terminal. In the virtual studio laboratory the students can choose one experiment content through the network, operate the experiment instrument through mouse or keyboard, 
observe experimental process, and analyse experimental results.

The virtual studio implemented in this paper belongs to desktop virtual reality system, based on Windows platform development, using 3ds max do model constructing, using the Vray model map baking rendering, combing with CAT for character action design, integrating all 3D objects to the virtual studio laboratory scene, realizing various interactive operation and scene roaming in Virtools platform, and making network issuance at last.

\section{THE DESIGN PURPOSE AND PRINCIPLES OF VIRTUAL STUDIO LABORATORY}

The purpose of the virtual studio laboratory in design and analysis mainly has two: the first one is building virtual studio laboratory environment used in class, practice teaching and amateur study by virtual reality technology, making the students experience the dynamic lifelike virtual learning form, mastering the basic course knowledge and experiment content, achieving the teaching goal efficiently and quality by combining with the traditional teaching, improving the students' comprehensive ability; the second one is making the students grasp related skills through this virtual studio laboratory, such as: light adjustment, shooting techniques and shooting views, etc. In order to achieve the design purpose mentioned above, we produce and realize the virtual studio laboratory, which includes studio scene, various lights and media instruments.

In the premise of having been clear about the design purpose, the virtual studio laboratory is designed and implemented according to the principles as follows:

- The laboratory interface is user-friendly.

- Virtual studio scene, lights and media instruments in it all strive to be consistent with real ones, achieve higher verisimilitude, and improve the efficiency as far as possible.

In the premise of ensuring experiment function, to guarantee real time of network transmission, the virtual studio laboratory being designed and implemented should make the 3D objects have facets as few as possible, compress all kinds of files, so as to improve the network transmission speed.

\section{THE MAIN FUNCTIONS OF VIRTUAL STUDIO LABORATORY}

Considering the need of teaching and practicing, the virtual studio laboratory includes six functions. Each function is described below.

\section{A. The general introduction of virtual studio laboratory}

This function is implemented by these methods: rambling in the virtual laboratory freely, voice explaining and sign guiding. This function can make the students know the main scene construction, layout and the functions of studio.

\section{B. The light introduction of virtual studio laboratory}

This function is implemented by 3D animations with voice and title. This function can make the students know various light types and lighting design in the studio.

\section{The experiment of light adjustment}

This experiment mainly shows the positions, directions and angle adjustment styles of the lights in virtual studio laboratory. The students adjust the lights located on the ceiling by stretch, rotate or slip adjustment, can carry out different lighting design setting. The experiment can make the students know various light adjustment methods of the studio, at the same time make them grasp different design methods of lighting design effect. The function is implemented by human-computer interaction technology. Through outer equipments such as mouse or keyboard operating the lights in virtual scene directly, the students can adjust and control the position and angle of the lights, so to get different light design effect.

\section{The experiment of shooting techniques}

This experiment mainly shows how to shoot views through operating video camera by using different techniques. It can make the students understand and grasp the shooting techniques of push, pull, shake and shift. The functions of this experiment are implemented by humancomputer interaction technology.

\section{E. The experiment of shooting views}

This experiment mainly shows how to shoot different views through operating video camera. It can make the students grasp the conception and shooting technique of different views. Through the shake or shift of video camera and the adjustment of push-pull button on the video camera, the students can shoot different views(such as: long shot, full shot, medium shot, close shot and close-up view). The modes of implementation and operation are same to (3).

\section{THE TECHNOLOGIES OF VIRTUAL STUDIO LABORATORY IMPLEMENTATION}

\section{A. Acquiring Real Scene Information}

In order to construct a virtual studio laboratory, first of all, we need acquire real studio scene information, take photos and measure size of real one and the objects in it. To the objects which need high fidelity we should take photos as samples, using them as model maps to post-production, to ensure the reality of virtual studio.

\section{B. Constructing 3D Entity Models}

According to real studio and its' functions we analyse the virtual studio experiment scene and the experiment equipments in it, determine the entity models, and then using the 3D modeling software establish the scene and 3D entity models in it. The experiment scene and virtual equipments in virtual studio laboratory need be simulated in figure and appearance. We should notice reduce the complication of the models. In order to ensure the reality of models, we should give the models materials or maps, or adjust the light to do baking map. The scene of virtual studio laboratory is constructed as the layout of real one, considering the house size and the position where the objects put at the same time. The models' structure such as walls, doors, windows and 
other objects are constructed in strict accordance with acoustic fitting-out standards[7].

\section{The Optimization of 3D Entity Models}

As known to all, the virtual studio laboratory needs realtime rendering, to ensure that, various optimizing measures have been and will be taken to the scene and object models construction. In the meantime of ensuring the reality of the models, we also need consider the limitation of hardware, internet bandwidth, virtual reality system's real-time demand and transmission rate restriction. So we have to follow a principle in modelling: under the precondition of ensuring the visual effects distortion, try to use the simplest models. All of these are to ensure we get optimized models.

\section{The Construction of Character Models and Actions}

There set two virtual characters according to the need of virtual studio laboratory: virtual guide character and virtual emcee character. The virtual guide character is used to guide the students through the ways of voice or gesture. The virtual emcee character is used to observe the emcee's illuminative effect after lighting design.

These two character models are constructed through the bones system of 3D max. To get true exterior, we set skin for them. According to the need of experiment we give the characters different actions separately. The guide character is given the actions of moving the lips, lifting arm, walk and wink. The emcee character is given the actions of moving the lips and wink.

\section{E. The Realization of Human-computer Real-time Interaction}

To the students, operating the experiment equipments really and controlling the evolvement of the experiment in the experiment item are important. Virtual studio laboratory realizes the real-time interaction of human, experiment environment and experiment equipments during the experiment through human-computer interactive technology, mainly include the ramble of the laboratory and the operation of the experiment equipments. Such as: light adjustment, shooting techniques and shooting views.

When we do lighting design by adjusting lights, through outer equipments such as keyboard or mouse we can rotate, slip or stretch every light on the stage ceiling. Through this way we can acquire various lighting design effect. These effects can fill the lighting need of different programs. We can acquire different shift or shake shooting effects through moving the virtual video camera with mouse, also can get different view effects through the video camera's pull or push button with mouse.

\section{F. Integration and Network Issuance}

The experiment scene and equipments are constructed alone, so we need integrate the virtual studio laboratory. The purpose of integration is to put the virtual scene and media equipments designed well into the virtual studio laboratory. Complementing the laboratory with other various media material to edit and synthesize (such as voice), the laboratory environment will be perfect and beautiful, the laboratory interface will be friendly, and all of these make welcome from the students.

In order to provide the integrated laboratory on the internet for the students to use, the laboratory need be issued on web.

The scenes of the virtual studio laboratory integrated and issued as shown like follow figures.

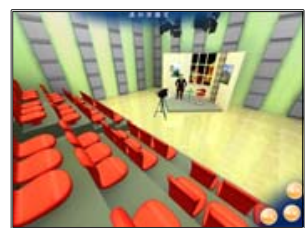

Figure1. Integrated scene 1

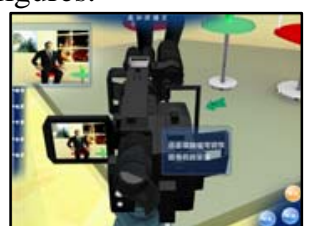

Figure2. Integrated scene 2

\section{The Meaning Analyse Of Virtual Studio LABORATORY}

\section{A. Saving Practice Space}

The virtual studio laboratory is constructed in computer, doesn't use real space and has large space superiority. If the computer has haven a connection to the network, the students can study or operate anywhere and anytime. So it has tremendous space advantage, help to solve the problem of building space lack in colleges and universities.

\section{B. Saving Construction Funds}

Virtual studio laboratory is constructed by software , can replace real studio environment, the virtual media equipments in it can replace various real ones, all of these can save expensive studio building cost and media equipments cost. All of these show that the virtual studio laboratory has obvious economic benefits. The other characteristic is resources sharing. The students can share experiment data, experiment equipments and experiment environment, etc., this characteristic can reduce repeating investment and economize investment cost greatly.

\section{Real-time Expanding of Experiment Instruments and Content}

With the amelioration of real media equipments', various equipment models in the virtual studio laboratory can be updated and replaced with real ones, and we don't need any funds but can keep up with the era development. Furthermore, the teaching content may change too, in order to agree with it the experiment content must change. The virtual laboratory experiment projects need timely expansion, reduction or modification, and the service function also wants to add or change at any time. The virtual studio laboratory has the characteristics in comprehensive management, resource sharing and so on, all of these provide low consumption, rapid and expanding characteristics in experiment projects, experiment equipments and experiment content change.

\section{Open Learning}

The virtual studio laboratory provides open learning. The students can choose study content, time and place freely. 
They can study in class with the teacher's explanation and do autonomous learning after class. They also can practice many times according to their master degree. We can see that the virtual studio laboratory gives the students full freedom. This type can enhance the students' knowledge understanding degree and professional technology level greatly. Furthermore, the students can realize the operation interaction between person and person, person and equipment, equipment and equipment with other students.

\section{E. Diversiform Applications}

The virtual studio Laboratory implemented in this paper can be used for conventional teaching environment, for example, in the classroom and experiment teaching, it also can be used in distance teaching. Whether which environment, the students can choose the experiment content by their interest and go into the related practice scene freely, and accomplish the experiment just like in real scene.

\section{CONCLUSION}

The application of virtual studio laboratory in colleges and universities teaching has produced a far-reaching influence: the improvement of experiment environment, the optimization of the teaching process, the rising of education technology level, the training of the students' practical ability, the exploration and development of modern education ideas, etc. It is useful to resolve the matters of space and fund lacking. The development and put into use of the virtual studio laboratory system has great significance, such as: injecting vigor for the remote experiment teaching, breaking through the laboratory of time, space and regional restriction, realizing taking the students as the main body, open learning and diversified education, achieving significant results of teaching.

The virtual studio implemented in this paper has been applied in the directing and producing of film and TV programs teaching in colleges and universities. The effect is good. The students not only understand and know the composing of real studio deeply, but also master knowledge such as: light types, light adjusting, lighting design, shooting views and shooting techniques, etc., improve the students' professional knowledge level and practice ability greatly.

\section{ACKNOWLEDGMENT}

This work is supported by the Education Science Research Project of Heilongjiang Province Association of Higher Education \#HGJXH B1110131, the Education Science Research Project of Heilongjiang Province Education Office \# GBC1211028, the Scientific and Technological Project of Heilongjiang Province Education Office \# 12511011 \& \# 12521050, the Higher Education Comprehensive Reform Pilot Special Project of Heilongjiang Province Education Office: to enhance university novice teachers' teaching capability through school-based training-taking northeast petroleum university as an example.

\section{REFERENCES}

[1] K. Curran, "An online collaboration environment," Education and information technologies, vol. 7. no. 2, pp. 41-53, November 2004.

[2] Bhargava, P. Antonakakis, J. Cunningham, C. Zehnder, A. T, "Webbased virtual torsion laboratory," Computer application in engineering education, vol. 14. no. 1, pp. 1-8, January 2006.

[3] B. Dalgarno, "The potential of 3D virtual learning environments: A constructivist analysis,” Electronic Journal of Instructional Science and Technology, no. 3, pp. 1-19, January 2002.

[4] Li Yalu, Hao Yingguang, Tang Zhenan, "Distance education and virtual laboratory ”, Chinese Journal of Nature, vol. 23. no. 3, pp. 157-160, March, 2001.

[5] L.D. Wu, Multimedia human-computer interaction technologies. Beijing, CN: National university of defense technology Press, 1999.

[6] X.M. Liu, Y. Zhao, J. Li, "The research of virtual laboratory for drilling well technologies based on web”, CCVRV'2004. 2004, pp. 661-664. 